\title{
Dynamic Viscoelastic Behavior of Dental Composites Measured by Split Hopkinson Pressure Bar
}

\author{
Yasuhiro TANIMOTO${ }^{1}$, Tsuyoshi NISHIWAKI ${ }^{2}$ and Kimiya NEMOTO ${ }^{1}$ \\ ${ }^{1}$ Department of Dental Biomaterials, Research Institute of Oral Science, Nihon University School of Dentistry at Matsudo, \\ 2-870-1, Sakaecho Nishi, Matsudo, Chiba 271-8587, Japan \\ ${ }^{2}$ Research and Development Department, ASICS Corporation, 6-2-1, Takatsukadai, Nishi-ku, Kobe 651-2271, Japan \\ Corresponding author, Yasuhiro Tanimoto E-mail:tanimoto.yasuhiro@nihon-u.ac.jp
}

Received September 12, 2005/Accepted January 23, 2006

\begin{abstract}
The present study evaluated the dynamic viscoelastic behavior of commercially available dental composites by a Split Hopkinson pressure bar (SHPB) test machine. Five commercially available composite resins - namely, two conventional hybrid composites (Filtek ${ }^{\mathrm{TM}}$ Z100, Z100; Filtek ${ }^{\mathrm{TM}}$ Z250, Z250), a packable composite (Filtek ${ }^{\mathrm{TM}} \mathrm{P} 60, \mathrm{P} 60$ ), a flowable composite (Filtek ${ }^{\mathrm{TM}}$ Flow, FL), and a nanofill composite (Filtek ${ }^{\mathrm{TM}}$ Supreme, SU) - were evaluated. By means of SHPB technique, the dynamic stress-strain curve, storage modulus, and loss tangent of the five dental composites were calculated. All specimens exhibited a nonlinear stress-strain curve in the loading process, which resulted not only from the viscoelasticity - but also from the plasticity - of matrix. In terms of storage modulus, no significant differences were exhibited among the five dental composites $(p>0.05)$. In terms of loss tangent, Z100 showed a significantly higher value than P60, FL, and SU ( $<<0.05)$. Within the limitations of this investigation using SHPB, it was indicated that the loss tangent increased with increasing filler content.
\end{abstract}

Key words: Dental composite, Dynamic viscoelastic properties, Split Hopkinson pressure bar

\section{INTRODUCTION}

Dental composites are commonly used as a restorative material for dental treatment ${ }^{1)}$. A dental composite is a dispersion-strengthened composite material composed of silica glass and dimethacrylate. To enhance bonding between silica and resin matrix, silica glass is treated with a silane coupling agent, which has a methacryloyl group at its terminal end ${ }^{2,3)}$.

It is well known that filler content, filler size, and matrix viscosity influence the mechanical properties of hybrid composites ${ }^{4-6)}$. Recently, two types of dental composite were developed - namely, packable $e^{7,8)}$ and flowable $e^{9,10)}$ composites. The introduction of these materials necessitates a new classification method, based on the viscosity of the composites. Packable composites, also called condensable composites sometimes, were introduced to the market with high expectations as an alternative to amalgam. They are characterized by a high filler load and a filler distribution that gives them a different consistency when compared with traditional hybrid composites. As for flowable composites, they build on the chemistry of traditional hybrid composites but contain smaller filler concentrations and in some instances, modified resin formulations. They are characterized by low elastic modulus and low viscosity, and that they improve the wettability of tooth structure. In addition, dental composites based on nanotechnology were recently developed ${ }^{11,12)}$. By leveraging recent advances in nanotechnology, nanofill composites that contain a unique combination of nanofillers and nanoclusters embedded in an organic polymer matrix are produced. They feature excellent strength and wear properties when compared with conventional hybrid composites.

Although the static behavior of dental composites has been documented, the dynamic response of new dental composites such as packable, flowable, and nanofill composites is not well known. To accurately predict the stability of new dental composites in oral functional conditions, stress analysis under impact force must be performed.

Measurement of dynamic viscoelastic behavior is a method that has been used to acquire useful information about dynamic behavior of dental resins ${ }^{13-16)}$. In this connection, a number of studies have reported on the dynamic viscoelastic behavior of composites using various dynamic test techniques and test conditions. For example, Fujii et $a .^{14)}$ investigated the dynamic viscoelastic properties of glass-fiber reinforced composite materials used for crowns and bridges. Likewise, Papadogiannis et $a .^{16)}$ evaluated the viscoelastic functions of four commercially available dental composites using a resonant dynamic mechanical analysis technique in torsion, and reported that composites with low loss tangent might show better clinical performance.

Split Hopkinson pressure bar (SHPB) is a unique method employed for dynamic experiments in various industrial fields ${ }^{17-20)}$. Traditionally, SHPB was used to investigate the dynamic behavior of metals ${ }^{18)}$. But 
of late, it has been used to study the constitutive properties of materials - such as composites and ceramics - under dynamic conditions of high strain rates and large strains. For example, Li et al. ${ }^{17)}$ investigated the dynamic behavior of a unidirectional graphite/epoxy composite material using SHPB analysis technique. He et $a l^{20)}$ also used SHPB to investigate the dynamic fracture behavior of layered alumina ceramics with dense and porous layers, and reported that it was the same as that of aluminum alloy foam. However, to date, studies investigating the viscoelastic behavior of new, commercially available composite resins such as packable and flowable composites using SHPB have not been published.

The purpose of the present study was to investigate the dynamic viscoelastic behavior of five commercially available dental composites by SHPB technique. The composites were thus selected so that effects of filler type could be evaluated.

\section{MATERIALS AND METHODS}

\section{Preparation of dental composites}

The composites evaluated in this study were supplied by 3M Dental Products, Japan. Two conventional hybrid composites (Filtek ${ }^{\mathrm{TM}}$ Z100, Filtek ${ }^{\mathrm{TM}}$ Z250), a packable composite (Filtek ${ }^{\mathrm{TM}} \mathrm{P} 60$ ), a flowable composite (Filtek ${ }^{\mathrm{TM}}$ Flow), and a nanofill composite (Filtek $^{\mathrm{TM}}$ Supreme) were evaluated. Table 1 lists the dental composites, their codes, lot numbers, and other information. All materials were of shade A3.

To fabricate the test specimens for dynamic analysis, the restorative composite pastes were placed in a circular gum mold $(5 \mathrm{~mm}$ diameter $\times 2 \mathrm{~mm}$ depth). Composite surface was covered with polyes- ter strips (Striproll, KerrHawe, Bioggio, Switzerland) and then the molded composite was pressed by a glass slide. By means of $\alpha$-LIGHT II ( $\mathrm{J}$ Morita Tokyo Mfg. Corp., Tokyo, Japan), surface was irradiated with visible light for 90 seconds. After polymerization, the composite was carefully removed from the mold. Both surfaces of the composite were polished using \#800 and \#1000 SiC papers under running water to remove residual monomers. Finally, the composites were stored in distilled water for one day at $37^{\circ} \mathrm{C}$.

\section{Experimental procedure}

A SHPB apparatus was used to generate the dynamic stress-strain curves of the prepared samples. Fig. 1 shows the schematic diagram of the SHPB apparatus used in this study, which consisted of two elastic pressure bars made of polymethyl methacrylate (PMMA). Samples were sandwiched between the input (incident) and output (transmit) bars, which were of $12 \mathrm{~mm}$ diameter. The bars were approximately $1000 \mathrm{~mm}$ long and supported by two bearings.

A PMMA striker bar of $80 \mathrm{~mm}$ length and 12 $\mathrm{mm}$ diameter was propelled toward the end of the input bar. Velocity was $376.8 \mathrm{~mm} / \mathrm{sec}$ and air pressure in the air gun was $0.6 \mathrm{MPa}$. On impact between the striker bar and input bar, an elastic compressive wave would be generated within the input bar. The energy wave was monitored by a strain gauge (KFG-1-350-C1-11, Kyowa Electric Instruments Co. Ltd., Tokyo, Japan). Strain gauges were bonded to both input and output bars with cyanoacrylate. For tests with the PMMA bars, their respective strain gauges were connected to a bridge amplifier

Table 1 Materials used

\begin{tabular}{|c|c|c|c|c|c|c|}
\hline ID & Material & Matrix monomer & $\begin{array}{l}\text { Composite } \\
\text { type }\end{array}$ & $\begin{array}{l}\text { Average filler } \\
\text { size }(\mu \mathrm{m})\end{array}$ & $\begin{array}{l}\text { Filler content } \\
\quad(\mathrm{vol} \%)\end{array}$ & Lot No. \\
\hline $\mathrm{Z} 100$ & Filtek $^{\mathrm{TM}} \mathrm{Z} 100$ & BisGMA, TEGDMA & Hybrid & $0.01-3.5$ & 66 & 20040824 \\
\hline $\mathrm{Z} 250$ & Filtek $^{\mathrm{TM}}$ Z250 & $\begin{array}{c}\text { UDMA, BisEMA, } \\
\text { BisGMA, TEGDMA }\end{array}$ & Hybrid & $0.01-3.5$ & 60 & 20040831 \\
\hline $\mathrm{P} 60$ & Filtek $^{\mathrm{TM}} \mathrm{P} 60$ & $\begin{array}{c}\text { UDMA, BisEMA, } \\
\text { BisGMA, TEGDMA }\end{array}$ & Packable & $0.01-3.5$ & 61 & 20041019 \\
\hline FL & Filtek $^{\mathrm{TM}}$ Flow & $\begin{array}{l}\text { BisGMA, TEGDMA, } \\
\text { Dimethacrylate polymer }\end{array}$ & Flowable & $0.01-6.0$ & 47 & 20040726 \\
\hline SU & Filtek $^{\mathrm{TM}}$ Supreme & $\begin{array}{c}\text { UDMA, BisEMA, } \\
\text { BisGMA, TEGDMA }\end{array}$ & Nanofill & $0.005-0.02$ & 60 & 20040402 \\
\hline
\end{tabular}

BisEMA: ethoxylated bisphenol-A-glycidyl methacrylate;

BisGMA: bisphenol-A-glycidyl methacrylate;

TEGDMA: triethylene glycol dimethacrylate;

UDMA: urethane dimethacrylate. 


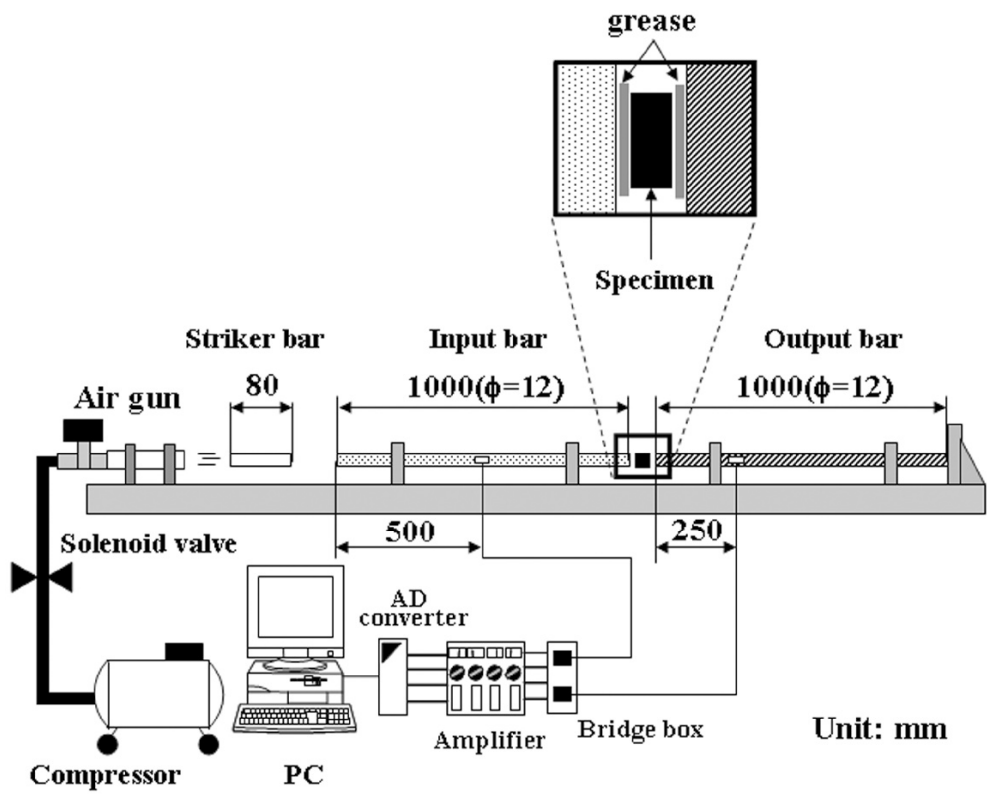

Fig. 1 Schematic diagram of the Split Hopkinson pressure bar (SHPB) test machine.

(DB-350A, Kyowa Electric Instruments Co. Ltd., Tokyo, Japan) in such a way that the output signal became proportional to the symmetric component of the strains. Thereafter, the output signal from the bridge amplifier would be fed to an amplifier (type 6M92, NEC-Sanei Co. Ltd., Tokyo, Japan) with a cut-off frequency set at $100 \mathrm{kHz}$.

At the interface between the input bar and the sample, the wave was partially reflected and partially transmitted into the sample. When the sample deformed, the strain rate and stress within the sample were related to the amplitudes of reflected wave and transmitted wave respectively. The input and reflected waves were recorded by the strain gauge bonded at the center of the input bar. The transmitted wave was recorded by the strain gauge bonded $250 \mathrm{~mm}$ from the end of the output bar. In addition, friction between the sample and input/output bars could be ignored because the sample was coated with grease.

Typical dynamic strain histories $\varepsilon_{\mathrm{IN}}, \varepsilon_{\mathrm{REF}}$, and $\varepsilon_{\mathrm{T}}$ representing input, reflected, and transmitted waves are shown in Fig. 2. Here the energy balance, $\varepsilon_{\mathrm{IN}}+\varepsilon_{\mathrm{REF}}=\varepsilon_{\mathrm{T}}$ is always satisfied. From the product of $\varepsilon_{\mathrm{T}}$, cross-sectional area and elastic modulus of bar, loading stress can be obtained. On the other hand, strain can be obtained from the integration of $\varepsilon_{\mathrm{REF}}$. The above technique gives information about the storage modulus that defines the elastic energy stored in the material. Loss tangent, which is the ratio of storage modulus and loss modulus, describes the dissipation of viscous energy relative to the stored elastic energy of the material. Data detected

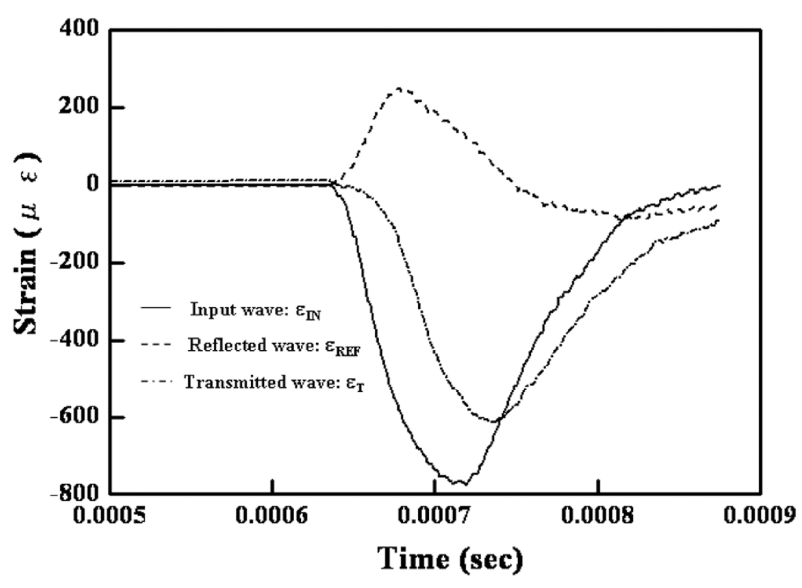

Fig. 2 Typical dynamic strain histories of input, reflected and transmitted waves.

using the SHPB apparatus were processed on a computer, and the storage modulus and loss tangent thereby calculated. Each experimental value was the average of four measurements.

\section{Statistical analysis of data}

Data were examined with analysis of variance (ANOVA) and tested by Fisher's multiple comparison test among the means with $\mathrm{p}<0.05$.

\section{RESULTS}

Typical dynamic stress-strain curves of materials are 
shown in Fig. 3. The average stress value of composites ranged from 17.73 to $19.16 \mathrm{MPa}$ and increased in the order from SU, P60, FL, Z100 to Z250. The average strain value of composites ranged from 0.0124 to 0.0148 and increased in the order from FL, P60, Z250, Z100 to SU.

Fig. 4 summarizes the storage moduli of five dental composites. The storage moduli of Z100, Z250, P60, FL, and SU were 0.691, 0.756, 0.740, 0.760, and $0.675 \mathrm{GPa}$ respectively. Thus, SU exhibited the lowest storage modulus. However, no significant differ- ences in storage modulus were observed among the different composites $(\mathrm{p}>0.05)$.

Fig. 5 shows the loss tangents of five dental composites. The loss tangents of Z100, Z250, P60, FL, and SU were $0.373,0.351,0.331,0.309$, and 0.326 respectively. Significant differences in loss tangent were observed among the different composites $(\mathrm{p}<0.05)$. Hybrid composite Z100 exhibited a significantly higher loss tangent than P60, FL, and SU $(p<0.05)$. Meanwhile, there were no significant differences in loss tangent between Z100 and Z250
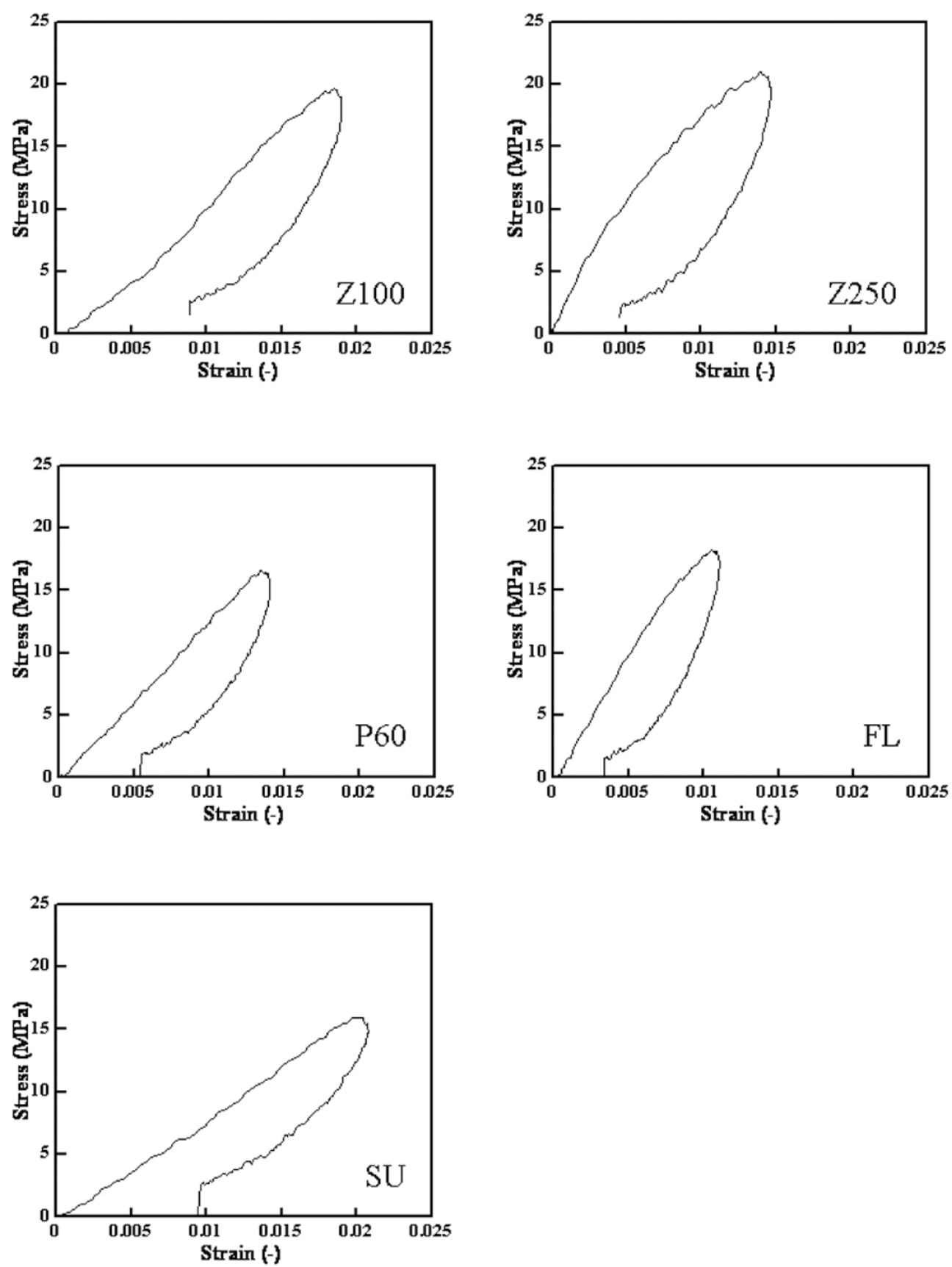

Fig. 3 Typical dynamic stress-strain curves of the five dental composites tested. 




Fig. 4 Storage moduli of the five dental composites.

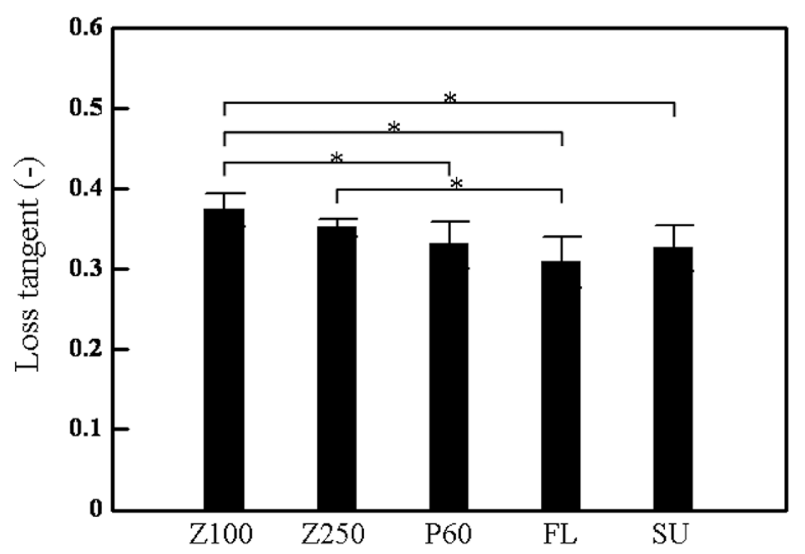

Fig. 5 Loss tangents of the five dental composites. Values connected by horizontal bars with '*' are significantly different from each other $(\mathrm{p}<0.05)$.

$(\mathrm{p}>0.05)$.

Fig. 6 shows the relationship between storage modulus and filler volume content, and between loss tangent and filler volume content. There was a weak relationship between storage modulus and filler volume content $(\mathrm{y}=-0.0032 \mathrm{x}+0.9141, \mathrm{r}=0.587)$. Conversely, there was a linear relationship between loss tangent and filler volume content $(y=0.0029 x+$ $0.1651, r=0.834)$.

\section{DISCUSSION}

Dental composites are normally composed of a dispersion of inorganic filler particles within a resin matrix. Based on recent advances in resin and filler technologies, new composites have henceforth been developed and evaluated by many researchers. Knobloch et $a{ }^{21)}$ investigated the relative fracture toughness of three packable composites, two conventional composites, and one laboratory-processed composite. They reported that the mean fracture

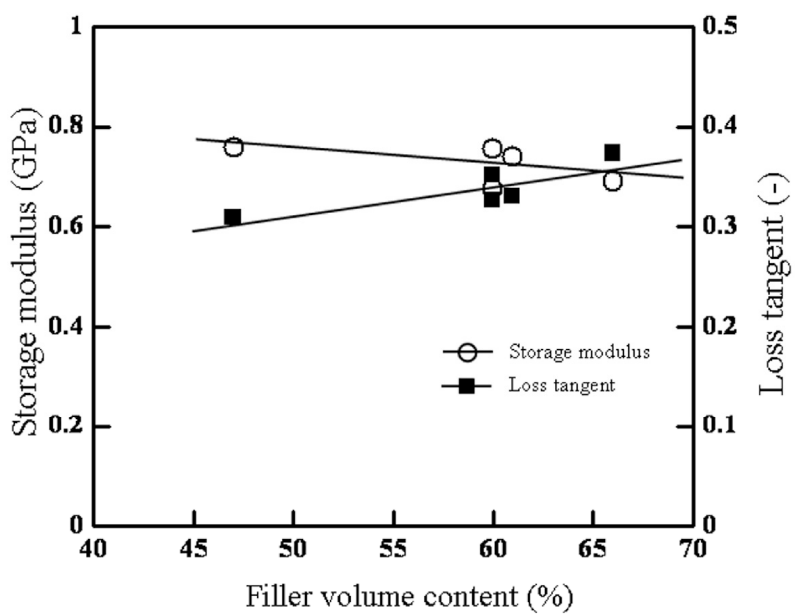

Fig. 6 Relationship between storage modulus and filler volume content, and between loss tangent and filler volume content.

toughness value of glass fiber-reinforced packable composite was significantly higher than any of the other composites. Tjandrawinata et $a l^{9)}$ evaluated the flexural properties of eight flowable light-cured restorative materials against two conventional restorative materials. They reported that the modulus of resilience of flowable composites was higher than that of conventional ones. Yap et $a l{ }^{22)}$ investigated the wear resistance of nanofill and hybrid composites, and reported that the wear resistance of nanofill composite was comparable or superior to hybrid composites. Nevertheless, to date, very little information is available regarding the dynamic viscoelastic behavior of new composite materials.

In the present study, five commercially available composites including new composites such as packable, flowable, and nanofill composites were tested to determine their dynamic properties using a SHPB apparatus. Tests were carried out using the composite resins and bars made of PMMA. Mousavi et $a l^{23)}$ also performed the SHPB test with PMMA bars and polypropylene specimens. They reported that good results were obtained for specimens with aspect ratios of diameter/length $=0.5,1.0$, and 2.5, whereas fair results were obtained for specimens with aspect ratio of 5.0. With a slight modification to that described by Mousavi and coworkers, we used a specimen $5 \mathrm{~mm}$ in diameter and $2 \mathrm{~mm}$ in length, corresponding to an aspect ratio of 2.5.

Based on the elastic properties of the bars and the recorded wave profiles, the dynamic stress-strain data in the specimen could be measured (Fig. 3). Stress-strain data recorded with the SHPB method were then used to evaluate the viscoelastic behavior of dental composites. Judging from Fig. 3, none of the specimens exhibited a linear stress-strain curve in the loading process. This resulted from not only the 
viscoelasticity, but also from the plasticity, of matrix.

In the present study, there were no significant differences in storage modulus among the five dental composites (Fig. 4). Meanwhile, storage modulus tended to decrease with increasing filler content $(r=0.587)$, as shown in Fig. 6. Z100 was filled with silica glass at $66 \mathrm{vol} \%$ with particle size ranging from $0.01-3.5 \mu \mathrm{m}$, and had a higher filler content than the other composites tested. Chung et al. ${ }^{24)}$ investigated the elastic modulus of resin-based dental composite restoratives such as hybrid (Z100, Z250) and flowable (Flow) composites using the microindentation test method. They showed that the indentation modulus of Z100 was significantly higher than Z250 and Flow. In the static test as reported by Chung and coworkers, the elastic modulus of the composite resins depended mainly on the filler content, because the elastic modulus of filler was much higher than that of matrix resin. On the other hand, in a dynamic test such as the SHPB method, the elastic modulus of matrix increases with strain rate $^{18)}$. This is due to the viscoelasticity of matrix resin. Further, with increasing filler volume content, the influence of matrix resin on storage modulus is decreased. This is another reason that account for the negative relation between filler volume content and storage modulus.

On the other hand, the loss tangent of Z100 was significantly higher than those of P60, FL, and SU (Fig. 5). In addition, the present study showed that the loss tangent increased with increasing filler content $(r=0.834)$, as shown in Fig. 6. However, contrary to our results, Papadogiannis et $a l .{ }^{25)}$ reported that composite resin with higher filler content showed the lowest value for loss tangent. Generally speaking, increasing filler content reduces the strain under constant stress. However, this phenomenon occurs in the linear region. As already mentioned in Fig. 3, the present results implied the effect of resin plasticity. This thus explains the disparity in our results with the previous study reported by Papadogiannis and cowokers.

Generally, the loss tangent determines macroscopic physical properties such as the damping for free vibrations, attenuation of propagated waves, and the frequency width of a resonance response ${ }^{25)}$. As already mentioned, the loss tangent is also an index of energy loss on deformation, and is an important factor for explaining viscoelastic behavior. Thus, it is thought that the properties of matrix resin have more influence to loss tangent compared with filler because the matrix resin is plastically deformed. Additionally, these would suggest that a high value of loss tangent is more effective for stress distribution in clinical situations.

From the results obtained in the present work, it is speculated that not only the filler content but also the properties of matrix resin influenced the dynamic viscoelastic properties of the composites. Although most of the composites used in the present study were based on BisEMA, BisGMA, UDMA, and TEGDMA, matrix properties such as resin composition and resin viscosity which affect both the storage modulus and loss tangent should be further investigated.

The handling characteristics of a composite resin exert significant influence in a restorative procedure. Packable composites for use in posterior restorations have been developed, and they have high viscosity and handling characteristics that are similar to amalgam. Meanwhile, flowable composites are characterized by low elastic modulus and low viscosity, in response to requests for easy handling properties. Ersoy et $a l .{ }^{26)}$ reported that packable composites are more suitable for posterior restorations. Miguez et $a l .{ }^{27)}$ reported that although the incremental technique prevented gap formation regardless of the use of a flowable resin, the use of a flowable composite did not guarantee gap-free restorations with improved bond strength of resin to dentin in bulk-filled restorations. On the overall, majority of researchers studying packable and flowable composites reported that ease of use and operator performances were useful for clinical applications. Thus, flowable and packable composites have potentials for use variously as restorative composites for different types of cavity. Although the investigation on viscoelastic properties has been thus summarized as above, more research is required to further examine the relationship between the handling characteristics of dental restorative applications and the dynamic viscoelastic behavior determined by SHPB.

In conclusion, within the limitations of this investigation, the hybrid composite (Z100) exhibited a higher loss tangent than other new dental composites such as packable composite, flowable composite, and nanofill composite. It was confirmed that the fillers contained in composites are principally responsible for the loss tangent.

\section{ACKNOWLEDGEMENTS}

The authors would like to acknowledge the contributions of 3M Corp. for supplying the composite materials. This work was supported in part by a grant from the Ministry of Education, Culture, Sports, Science and Technology to promote 2001-Multidisciplinary Research Projects (in 2001-2005).

\section{REFERENCES}

1) Phillips RW. Skinner's science of dental materials, 7th ed, WB Saunders Co, Philadelphia, 1973, p.232.

2) Yoshida Y, Shirai K, Shintani H, Okazaki M, Suzuki K, van Meerbeek B. Effect of presilanization filler de- 
contamination on aesthetic and degradation resistance of resin composites. Dent Mater J 2002; 21: 383-395.

3) Arksornnukit M, Takahashi H, Nishiyama N. Effect of silane coupling agent amount on mechanical properties and hydrolytic durability of composite resin after hot water storage. Dent Mater J 2004; 23: 31-36.

4) Asmussen E, Peutzfeldt A. Influence of UEDMA, BisGMA and TEGDMA on selected mechanical properties of experimental resin composites. Dent Mater 1998; 14: $51-56$.

5) Adabo GL, dos Santos Cruz CA, Fonseca RG, Vaz LG. The volumetric fraction of inorganic particles and the flexural strength of composites for posterior teeth. J Dent 2003; 31: 353-359.

6) Tanimoto $Y$, Nemoto $K$. Influence of particle size of fillers on frictional wear of dental composite resins. Compos Interface 2004; 11: 15-24.

7) Choi KK, Ferracane JL, Hilton TJ, Charlton D. Properties of packable dental composite. J Esthet Dent 2000; 12: 216-226.

8) Bayindir YZ, Yildiz M, Bayindir F. The effect of "softstart polymerization" on surface hardness of two packable composites. Dent Mater J 2003; 22: 610-616.

9) Tjandrawinata R, Irie M, Suzuki K. Flexural properties of eight flowable light-cured restorative materials, in immediate vs 24-hour water storage. Oper Dent 2005; 30: 239-249.

10) Han L, Okamoto A, Fukushima M, Okiji T. Enamel micro-cracks produced around restorations with flowable composites. Dent Mater J 2005; 24: 83-91.

11) Mitra $\mathrm{SB}, \mathrm{Wu} \mathrm{D}$, Holmes $\mathrm{BN}$. An application of nanotechnology in advanced dental materials. J Am Dent Assoc 2003; 134: 1383-1390.

12) Yap AUJ, Lim LY, Yang TY, Ali A, Chung SM. Influence of dietary solvents on strength of nanofill and ormocer composites. Oper Dent 2005; 30: 129-133.

13) Fujii K, Tsukada G, Ueno O, Imaizumi A, Masuda A, Inoue K. Dynamic viscoelastic properties in torsion of four commercially available resins for crown and bridge. Dent Mater J 1998; 17: 205-212.

14) Fujii K, Arikawa $H$, Kanie $T$, Hamano $T$, Nishi $Y$, Nagaoka E. Dynamic viscoelastic properties of commercial glass-fibre reinforced resin used for crowns and bridges. J Oral Rehabil 2002; 29: 827-834.

15) Sakaguchi RL, Shah NC, Lim BS, Ferracane JL, Borgersen SE. Dynamic mechanical analysis of storage modulus development in light-activated polymer matrix composites. Dent Mater 2002; 18: 197-202.

16) Papadogiannis $Y$, Boyer DB, Helvatjoglu-Antoniades M, Lakes RS, Kapetanios C. Dynamic viscoelastic behavior of resin cements measured by torsional resonance. Dent Mater 2003; 19: 510-516.

17) Li Z, Lambros J. Determination of the dynamic response of brittle composites by the use of the split Hopkinson pressure bar. Compos Sci Technol 1999; 59: 1097-1107.

18) EI-Magd E, Brodmann M. Influence of precipitates on ductile fracture of aluminium alloy AA7075 at high strain rates. Mater Sci Eng 2001; A307: 143-150.

19) Dai LH, Liu LF, Bai YL. Effect of particle size on the formation of adiabatic shear band in particle reinforced metal matrix composites. Mater Lett 2004; 58: 1773-1776.

20) He Z, Ma J, Wang H, Tan GEB, Shu D, Zheng J. Dynamic fracture behavior of layered alumina ceramics characterized by a split Hopkinson bar. Mater Lett 2005; 59: 901-904.

21) Knobloch LA, Kerby RE, Seghi R, Berlin JS, Clelland N. Fracture toughness of packable and conventional composite materials. J Prosthet Dent 2002; 88: 307-313

22) Yap AUJ, Tan CH, Chung SM. Wear behavior of new composite restoratives. Oper Dent 2004; 29: 269-274.

23) Mousavi S, Welch K, Valdek U, Lundberg B. Nonequilibrium split Hopkinson pressure bar procedure for non-parametric identification of complex modulus. Int J Impact Eng 2005; 31: 1133-1151.

24) Chung SM, Yap AUJ, Tsai KT, Yap FL. Elastic modulus of resin-based dental restorative materials: A microindentation approach. J Biomed Mater Res Part B: Appl Biomater 2005; 72B: 246-253.

25) Papadogiannis Y, Helvatjoglu-Antoniades M, Lakes RS. Dynamic mechanical analysis of viscoelastic functions in packable composite resins measured by torsional resonance. J Biomed Mater Res Part B: Appl Biomater 2004; 71B: 327-335.

26) Ersoy M, Civelek A, L'hotelier E, Say EC, Soyman M. Physical properties of different composites. Dent Mater J 2004; 23: 278-283.

27) Miguez PA, Pereira PNR, Foxton RM, Walter $R$, Nunes MF, Swift Jr. EJ. Effects of flowable resin on bond strength and gap formation in class I restorations. Dent Mater 2004; 20: 839-845. 